\title{
Children with medical complexity and paediatric palliative care: data by a respiratory intermediate care unit
}

\author{
Serena Caggiano ${ }^{1}$, Martino Pavone $^{1}$, Claudio Cherchi ${ }^{1}$, Maria Giovanna Paglietti ${ }^{1}$, \\ Alessandra Schiavino ${ }^{1}$, Francesca Petreschi ${ }^{1}$, Beatrice Chiarini Testa ${ }^{1}$, and Renato Cutrera ${ }^{1}$ \\ ${ }^{1}$ Bambino Gesù Children's Hospital IRCCS
}

May 6, 2021

\begin{abstract}
Pediatric palliative care (PPC) is an active and total approach to the care of children with life-limiting conditions and to their families. PPC programs provide ongoing care for children with medical complexity (CMC), many of whom will reach adulthood. The aim of the study is to describe a population of CMC afferent in 4 months to the Intermediate Care Unit of a tertiary referral hospital for southern and central Italy. We enrolled all CMC patients admitted at our unit in 4 randomized months. We registered pathologies and different categories of childhood diseases, devices and needs, hospitalization and home care plan. Among 195 admitted to our unit, $87 \mathrm{CMC}$ were included. Median age was $9(0.1-35.7)$ years. The main pathologies recorded were neuromuscular, neurological, respiratory, metabolic, malformative, genetic syndromes and outcomes of prematurity. Comorbidity made by respiratory, digestive, neurological, cardiac and urological involvement was present in a high percentage of cases. Among our patients, only 24 hadn't any devices. The average length of hospitalization was 7.0 $(1.0$ - 270.0) days with $2(1.0-7.0)$ admissions per year for patient. Home care activation was not required for only 24 of 87 patients. Children eligible for CPP are increasing and their survival results in a rise in comorbidities and special needs demanding multi-level interventions. Respiratory symptoms are the most recurrent observed demonstrating the need for an expert in CPP to have respiratory skills. Sharing data and knowledge of CMC needs may help to improve care coordination and interventions.
\end{abstract}

\section{Hosted file}

Caggiano_ChildrenWithMedicalComplexityAndPaediatricPalliativeCare.pdf available at https://authorea.com/users/412218/articles/520986-children-with-medical-complexity-andpaediatric-palliative-care-data-by-a-respiratory-intermediate-care-unit

\section{Hosted file}

tables.pdf available at https://authorea.com/users/412218/articles/520986-children-withmedical-complexity-and-paediatric-palliative-care-data-by-a-respiratory-intermediatecare-unit

\section{Hosted file}

Fig.pdf available at https://authorea.com/users/412218/articles/520986-children-withmedical-complexity-and-paediatric-palliative-care-data-by-a-respiratory-intermediatecare-unit 